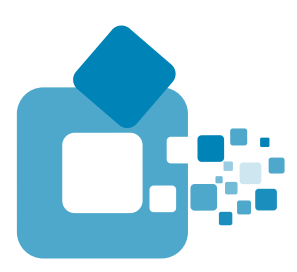

\title{
Kitapların Dünyasında Edebî Aydınlanma \\ Türk Dili ve Edebiyatı Konularının Etkili öğretimi Iç̧in Edebi Eserlerden Yararlanma: Mai ve Siyah ile Servet-i Fünûn Örneği
}

Literary Enlightenment In the World of Books Literary Works for Effective Teaching of Turkish Language and Literature: Example of Mai \& Black and Servet-i Fünûn

\section{Firdevs Nur ALGÜL ${ }^{1^{\star}}$}

${ }^{1}$ Beşiktaş Bilim ve Sanat Merkezi, İstanbul / Türkiye ${ }^{1}$ Beşiktaş Science and Art Center, Istanbul / Turkey *firdevs_nur_algul@hotmail.com ${ }^{1}$ ORCID: 0000-0002-3027-7946

\section{Sibel SELÇUK ${ }^{2}$}

${ }^{2}$ Beşiktaş Bilim ve Sanat Merkezi, İstanbul / Türkiye ${ }^{2}$ Beşiktaş Science and Art Center, Istanbul / Turkey

${ }^{2}$ ORCID: 0000-0002-7233-0389

\section{MAKALE BİLGISİ / ARTICLE INFORMATION \\ Geliş Tarihi / Date Received \\ 22.05.2019 \\ Yayın Tarihi / Date Published \\ Aralık / December 2019 \\ Kabul Tarihi / Date Accepted \\ 17.12.2019 \\ Yayın Sezonu / Pub Date Season \\ Aralık-Haziran / December - June}

\section{ATIF / CITE as}

Algül, F. N. ve Selçuk, S. (2019). "Kitapların Dünyasında Edebî Aydınlanma Türk Dili ve Edebiyatı Konularının Etkili Öğretimi İçin Edebi Eserlerden Yararlanma: Mai ve Siyah ile Servet-i Fünûn Örneği” / "Literary Enlightenment In the World of Books Literary Works for Effective Teaching of Turkish Language and Literature: Example of Mai \& Black and Servet-i Fünûn". bilar: Bilim Armonisi Dergisi, 2 (2): 45-51. doi: 10.37215/bilar.2019257648

\section{https://dergipark.org.tr/tr/pub/bilar}

Copyright (C) Published by Antalya İl Millî Eğitim Müdürlüğü Since 2018, Antalya, 07100 Turkey. All rights reserved. 


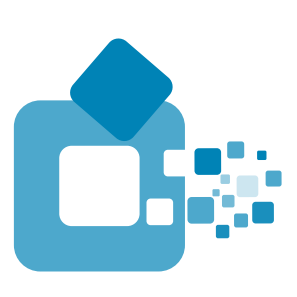

Kitapların Dünyasında EdebîAydınlanma

Türk Dili ve Edebiyatı Konularının Etkili öğretimi Iç̧in Edebi Eserlerden Yararlanma: Mai ve Siyah ile Servet-i Fünûn Örneği

Literary Enlightenment In the World of Books Literary Works for Effective Teaching

of Turkish Language and Literature: Example of Mai \& Black and Servet-i Fünûn

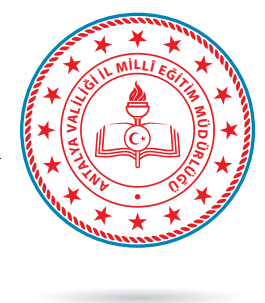

\section{ÖZET}

Etkili okuma, düşünme, anlama ve ifade etme becerisinde önemli bir yeri olan edebiyat dersi; estetik zevkin gelişmesi, kültürel değerlerin somut olarak ifade edilmesi ve yorumlanması, sürdürülen hayatın farklı bir dikkat ve duyarlılıkla dile getirilmesi bakımlarından önemlidir. Edebiyat dersi müfredatında edebiyat tarihi de mühim bir yer tutmaktadır. Ancak dersin genel amaçları göz önünde bulundurulduğunda, literatürde derste uygulanan yöntemlerin, kazanımları elde etmede yetersiz kaldığı görülmektedir. Öğrencilerin ezbere dayalı e ğitim sistemi yerine bizzat bilgiyi kendisi keşfederek özümsemesi gerekmektedir. Araştırmamızda örnek uygulama olması bakımından Türk dili ve edebiyatı dersinin bölümlerinden Servet-i Fünûn edebiyatının öğrencilere kavratılmasında dönemin sanatçılarından H. Ziya'nın “Mai ve Siyah" romanına ayrıca bir materyal işlevi yüklenerek edebi dönemin sanat anlayışını, sosyal-siyasi-kültürel durumunu, üslup özelliklerini kavratmada somutlaştırıcı, etkili bir materyal olarak kullanılmasının imkânları, eleştirel okuma ve metin tahlili yöntemleri kullanılarak ortaya konulmuştur. Literatüre ve romana dayalı ortaya koyulan veriler, ayrıca ders öğretmen ve öğrenci görüşüne sunularak test edilmiştir. Roman analiz edildiğinde ilgili dönemin özellikleri bilgi ve uygulama olarak iki şekilde karşımıza çıkmaktadır. Servet-i Fünun sanatçılarının düşüncelerini, sosyal hayatlarını, kişiliklerini ve dönemin yapısını anlatan etkili sözler ve yaşam kesitleri okuyucuya sunulmaktadır. Şiir poetikalarıyla roman karakterlerinden Hüseyin Nazmi, Tevfik Fikret'i; Raci, Muallim Naci'yi, Ahmed Cemil, Cenap Şehabettin'i temsil etmektedir, bu bakımdan romanın Servet-i Fünûn edebiyatını öğrencilere öğretmede etkili olacağı sonucuna varılmıştır. Bu gibi özelliklere sahip eserlerle edebiyat bilgilerinin çok daha akılda kalıcı hâle geleceği sonucuna varılmıştır.

Anahtar Sözcükler: Mai ve Siyah, Servet-i Fünûn, Eleştirel Okuma, Etkili Öğretim.

\section{ABSTRACT}

Literature course has an important place in effective reading, thinking, understanding and expression skills; it is important for the development of aesthetic taste, for expressing and interpreting cultural values in a concrete way, and for expressing the living life with different attention and sensitivity. The history of literature also has an important place in the curriculum of the literature course. However, considering the general objectives of the course, it is seen in the literature that the methods applied in the course are insufficient to obtain gains. Instead of a rote-based education system, students must discover and absorb information by themselves. In our study, in terms of exemplary practice, Servet-i Fünûn literature, one of the sections of Turkish Language and Literature Course, was introduced to H. Ziya's novel "Mai and Siyah" who is an artist of the period and the possibilities of using it as an embracing, effective material in comprehension have been demonstrated by using critical reading and text analysis methods. The data presented in the literature and novel were also tested and presented to the teachers and students. When the novel is analyzed, the characteristics of the relevant period appear in two ways as information and practice. Servet-i Fünun artists' thoughts, social lives, personalities and the structure of the period, telling the effective words and life sections are presented to the reader. Hüseyin Nazmi, one of the novel characters with poetics, Tevfik Fikret; Raci, Muallim Naci, Ahmed Cemil, Cenap Şehabettin represent, in this respect, it is concluded that the novel will be effective in teaching Servet-i Fünûn literature to students. It has been concluded that literary knowledge will become more memorable with such works.

Keywords: Mai and Siyah, Servet-i Fünûn, Critical Reading, Effective Teaching. 


\section{Gíriş}

Edebiyat eğitimi; bireylerin estetik zevklerinin geliştirilmesini, kültürel değerleri benimsemelerini ve yorumlamalarını, sürdürülen hayatı farklı bir şekilde dile getirmeleri açısından oldukça önemlidir. Edebi eser, dille gerçekleşen güzel sanat ürünüdür. Özgünlüğü de tarih ve kültür ile olan yakınlığından almıştır. Edebî metin, sanatın ve kültürün bir arada bulunduğu alanda oluşur. Zaten dil, kültür alanının hem yapı taşı hem de ifade yöntemidir. $\mathrm{Bu}$ durum edebiyat eğitimine, kültür ve sanat eğitimi arasında ayrı bir önem kazandırmaktadır. Edebi metinler, sanat aracılığıyla kültürel değerleri yaşamın gerçekliğinden hareketle somutlaştırır. Edebiyat dersi programı, Türk edebiyatı derslerinde öğrencilerin metinleri önce çözümlemeleri; anlam ve anlatım bakımlarından incelemeleri; sonra da elde ettikleri bu bilgiler üzerinden yorumlamalarını sağlamak amacıyla hazırlanmıştır. Öğrencilerin Türk edebiyatı derslerinde amacını ve niteliğini bilmeden ezberledikleri bilgiler yerine metin tahlili yapma, eleştirel okuma ve anlama becerilerini kazanmaları ve bunlardan yararlanarak yaşamın zevkine varmaları amaçlanmıştır (MEB 2011).

Ortaöğretim 9.-12. sınıflar Türk edebiyatı dersi öğretim programı (MEB 2011), “Tarih İçinde Türk Edebiyatı" ünitesinde hedeflenen kazanımların bazıları şunlardır:

- Uygarlık tarihiyle edebiyat tarihi arasındaki ilişkileri açıklar.

- Türk edebiyatının dönemlere ayrılmasının sebeplerini açıklar.

- Edebi dönemlerin zihniyetle ilişkisini sorgular.

- Edebi dönemleri belirleyen hâkim zihniyeti açıklar.

- Türk edebiyatındaki dönemlerin ayırıcı özelliklerini belirler.

Edebiyat dersinin amaçları içerisinde yer alan edebiyat tarihi ve dönemleri bilgilerinin ezbere dayalı, öğretmen merkezli bir eğitim yöntemi ile öğrencilere verilmesi öğrencilerin konuları kavramasında zorluk yaşatmaktadır. Bunun yerine öğrencilerin edebiyat dersi müfredatında da yer alan konuların kurgulanarak okuyucuyu olay içinde yaşatan roman ve öyküler yoluyla anlatıp kavratmak çok daha kolay olacaktır. Örneğin edebi akımların özelliklerini bilgi olarak vermek yerine bu edebi akımların en iyi temsilcisi niteliğinde eserleri edebiyat halkasi (Karatay 2015) gibi nitelikli okumaya teşvik edici yöntemlerle okutup üzerinde düşündürmek öğrencilerin hem ders konusunu önündeki somut örnek ile bizzat kendi çabası ile özümseyerek öğrenmesini sağlayacak hem de okuma alışkanlığını kazanmasında yardımcı olacaktır.

Ortaöğretimde 4 yıl boyunca Türk edebiyatı dersi adı altında günümüz Türk edebiyatının oluşumunda etkili olan edebi dönemler önemli bir yer tutmaktadır. Modern Türk edebiyatının oluşumunda mühim bir evre olan Servet-i Fünûn edebiyatı gerek kullanılan dil, gerekse sanat anlayışı olarak öğrenciler tarafından kavranması zor bir konu durumundadır. Döneme adını veren Servet-i Fünûn dergisi ilk çıktığı dönemlerde fen dergisi olarak yayınlanmıştır. Bu dergi Tevfik Fikret yazı işleri müdürlüğüne geldikten sonra sadece bir dergi olmakla kalmayarak Türk edebiyatının yenileşme sürecinde önemi göz ardı edilemeyecek olan bir organ hâline gelmiştir (Memic ve Doğan 2016). Servet-i Fünûn edebiyatı 1896 - 1901 yıllarını kapsamaktadır. Bu edebiyat Servet-i Fünûn dergisi çevresinde toplanan; Tevfik Fikret, Cenab Şahabeddin, Ali Ekrem, Süleyman Nesib gibi şairler ile Halit Ziya, Mehmed Rauf, Hüseyin Cahit, Ahmet Hikmet ve Safveti Ziya gibi yazarların hazırlamış olduğu eserlerden oluşmaktadır (Çakır 2009). Bu dönemde "Sanat sanat içindir." anlayışı benimsenmiştir. Eserlerde genel olarak bireysel konular işlenmiş, toplumsal konulara değinilmemiştir. Dönemin siyasi yapısı yazar ve şairlerin toplumsal olayları içeren eserler kaleme almalarını engelleyerek bireyin iç dünyasına yönelmelerine neden olmuştur. Servet-i Fünûn yazarları eserlerinde ağır bir dil kullanmışlardır. Halk diliyle yazma geleneği bir kenara itilmiş, konuşma dilinden uzak, Servet-i Fünûncular arasında anlaşılan saklı bir şiir dili ve üslup meydana gelmiştir (Memic ve Doğan 2016). Cümlelerinde ara ara Fransızca ve Arapça kelimeler bulunmaktadır. Söz diziminde yenilikler yapmışlar, kesik cümleler kullanmışlar, sıfatları ismin sonunda kullanmışlar, fiilsiz cümleler oluşturmuşlar "ve" bağlacına, "ah" ve "oh" gibi ünlemlere cümlelerde sıkça yer vermişlerdir. Cümleleri uzun yazmışlardır. Şiir ve romanlarında düş-gerçek ilişkisine sıkça rastlanmaktadır. Romanda realizm yani gerçekçilik, şiirlerinde ise Parnasizm ve Sembolizm bulunmaktadır. Parnasizm şiirde gerçekçilik sembolizmde kapalı anlatım-sembolik anlatım anlamına gelmektedir. Aruz ölçüsü bu dönemde de bulunmaktadır. Fakat şairler şiirlerinde tek bir aruz ölçüsü kullanmaktansa her duygu için farklı aruz ölçüsü kullanmayı uygun görmüşlerdir. Servet-i Fünûn edebiyatının en önemli özelliklerinden biri de yazar ve şairlerin edebi eserde şekil bütünlüğüne ve mükemmelliğine, dil ve üsluba, bu doğrultuda da ahenk ve musikiye önem vermiş olmasıdır (Çakır 2009). Edebiyat tarihimizde Servet-i Fünûn devrinin diğer dönemlerden farkını ve önemini Akyüz (1990, 88) şu şekilde ifade eder: "Servet-i Fünûn yahut Edebiyat-1 Cedide devri, Türk edebiyatında $1860^{\prime}$ tan beri devam eden Doğu-Batı mücadelesinin 
kesin sonucunu - Batı edebiyatının lehine olaraktayin eden sonuncu safhasıdır. Gerçekten pek yoğun ve pek dinamik çalışmalarla geçen bu sıcak safhanın sonunda Türk edebiyatı, gerek zihniyet, gerek temalar ve gerekse teknik bakımlardan tamamıyla Avrupai bir mahiyet kazanabilmiştir." Bu dönemde ön plana çıkan türlerden biri de romandır. Tanzimat Döneminde ilk örnekleri verilmeye çalışılan romanın bu dönemde Batılı yöntemlere uygun Avrupai örnekleri başarıyla sergilenir. Türk edebiyatında "romancılığın babası" olarak kabul edilen Halit Ziya Uşaklıgil'in bu başarıda oldukça önemli bir payıvardır (Baş 2010).

Halit Ziya Uşaklıgil batılı anlamda ilk roman olan ve dönemin basın, edebiyat ve şiir hayatıyla ilgili önemli gözlemleri içeren Mai ve Siyah kitabını yazarak edebiyat dünyasında tanınmıştır. Halit Ziya Mai ve Siyah kitabında Servet-i Fünûn edebiyatını ve dönemini romanın başkarakteri olan Ahmed Cemil'in gözünden anlatmıştır. Dolayısıyla Mai ve Siyah romanını okuyarak Servet-i Fünûn dönemi özelliklerini, sanat anlayışını, zihniyetini, yaşanan dönemin sosyo-kültürel hayatını, sanatçılarının yaşamlarından kesitleri vb. pek çok hususa dair bilgiyi kolayca kavramak mümkündür. Halit Ziya Uşaklıgil Mai ve Siyah romanında dönemin yazar ve şairlerini tek tek anlatmak, dönemin özelliklerini her yönüyle temsil etmek yerine Ahmed Cemil karakterini oluşturmuştur. Talim Terbiye Kurulu Başkanlığ 1 (2011), “edebi devir, kişilik ve metin hakkında önceden hazırlanmış bilgileri vermenin beklenen yararı sağlamadı̆̆ı düşüncesiyle; öğrencilerin metinleri çözümleyerek kendi kendilerini zevk, anlayış, beceri ve bilgi bakımlarından zenginleştirmelidir" demektedir. Türk dili ve edebiyatı dersinin 11. sınıf müfredatında yer alan ve Türk edebiyatına yön veren önemli devirlerden olan Servet-i Fünûn dönemini, dersin amaçları doğrultusunda Mai ve Siyah romanı ile kalıcı ve etkili şekilde öğrenmek mümkündür. Büyük hayaller ve umutlarla başlayıp hayal kırıklığı içinde son bulan Servet-i Fünûn dönemi gibi, mai yıldızlı bir gecede başlayıp siyah bir gecede son bulan romanin adındaki "mai" Ahmed Cemil'in ve temsil ettiği Servet-i Fünûn şairlerinin hayallerini, "siyah" ise hayat(lar)ının gerçeklerini yansıtmaktadır ki Servet-i Fünûn edebiyatı da büyük hayallerle başlayıp, Hüseyin Cahit'in Fransızcadan çevirdiği "Edebiyat ve Hukuk" adlı yazının dergide yayımlanması ve bu durum sonucunda Servet- i Fünûn dergisinin kapatılmasıyla (Ekim 1901 Sayı 553) son bulmuştur (Kılıç Gündoğdu 2009). Mai ve Siyah romanı bu haliyle içerik ve üslup olarak aynı zamanda etkili bir öğretim materyali özelliği taşımaktadır.

\subsection{Araştırmanın Amacı ve Önemi}

Çeşitli yönlerden bilinçli, kendinden emin ve başarılı bireyler yetiştirmenin önemi her geçen gün artmaktadır. Öğretim sürecinin her aşamasında öğrencilerin bireysel ve grup halinde öğrenme, eleştirel düşünme ve okuma becerilerinin geliştirilmesi öğrencilerin bilinçli bireyler olarak yetişmelerini sağlar. Edebi eserler ile birlikte eleştirel düşünme ve okuma becerilerinin geliştirilmesi eskiye dayanan bir yöntemdir. (Karatay 2015). Türk edebiyatı dersi konularının etkili öğrenilip özümsenmesinde de konuyla ilgili kitaplar büyük öneme sahiptir. Halit Ziya Uşaklıgil'in Mai ve Siyah romanı bu nitelikte bir romandır. 9.-12. sınıf müfredatında öğrencilerde (MEB 2011):

1. Servet-i Fünûn edebiyatını etkileyen sosyal, siyasal ve kültürel ortamın yapısını açıklar,

2. Servet-i Fünûn dönemini etkileyen sanat, edebiyat ve düşünce akımlarını metinlerden hareketle belirler,

3. Servet-i Fünûn edebiyatının Tanzimat edebiyatından ayrılan yönlerini açıklar.

gibi davranışlar kazandırmak hedeflenmiştir. Bu hedeflere ulaşmada dönemin romanı Mai ve Siyah'ın önemli, zengin bir materyal özelliği taşıdı̆̆ını ortaya koymak amacıyla metin tahlili yoluyla Mai ve Siyah romanında Servet-i Fünûn edebiyatının izleri aranacak, romandan alıntilarla ve kaynaklara dayanarak ortaya konulmaya çalışılacaktır. Bilgi aktarımı yerine Mai ve Siyah romanı atmosferinden çeşitli örnekler vererek Servet-i Fünûn edebiyatı özelliklerini, dünya görüşünü, sanat anlayışını somutlaştırıp ve daha anlaşılabilir hale getirmek, elde edilen verileri eğitim-öğretim sisteminin hizmetine sunmak ve örnek olmak bakımından önemli bir çalışmadır.

\section{MATERYAL VE METOT}

Servet-i Fünûn edebiyatı ve Mai ve Siyah romanı hakkında ayrıntılı literatür taraması yapılmıştır. Araştırmalardan sonra Halit Ziya Uşaklıgil'in Mai ve Siyah romanı eleştirel okuma ve metin tahlili yöntemleri ile analiz edilerek okunmuştur. Metin tahlili, metin çalışmalarının son aşaması olup günümüzde metin incelemesi, metin çözümlemesi olarak da bilinmekte ve kullanılmaktadır. Metin incelemelerinde, metnin biçim özelliklerinden, içeriğinden, edebî sanatlarından, sanatçının iç dünyasından, sanatçının toplum ve dönemle olan ilişkisinden, dolayısıyla metinin içerisinde oluşturulan hayal, duygu, düşünce dünyasından vb. özelliklerinden bahsedildiği görülür (Mengi 2007). Romanda Servet-i Fünûn edebiyatının çeşitli açılardan özelliklerini somutlaştıran, ön plana çıkan ilgili bölümler not alınmıştır. Tespit edilen devir özellikleri ve sanat anlayışı, literatürdeki 
bilgilerle karşılaştırılmış ve böylece Mai ve Siyah romanında Servet-i Fünûn edebiyatının yansımaları ortaya konulmuştur.

\section{BULGULAR}

$\mathrm{Bu}$ araştırma, Mai ve Siyah romanı, Can Yayınlarının 2016 yılı baskısı üzerinde yapılmıştır.

Servet-i Fünûn edebiyatında şairler anlatılmak isteneni sadece anlam olarak değil de ses olarak da anlatılmasını istemektedirler. Bu düşünceyi romanda 24-25. sayfalarında Mir'atı Şuun on birinci senesine girilmesi üzerine sadece gazete yazarlarına verilen ziyafette Ahmed Cemil şu ifadelerle anlatmaktadir:

"Bilseniz, şiirin nasıl bir dile muhtaç olduğunu bilseniz! Öyle bir dil ki... Neye benzeteyim bilmem! Söyleyen bir ruh kadar açık olsun, bütün kederlerimize, sevinçlerimize, düşüncelerimize, o kalbin bin türlü inceliklerine, düşüncenin bin çeşit derinliklerine, heyecanlara, öfkelere tercüman olsun; bir dil ki bizimle birlikte gurubun hüzünlü renklerine dalsın düşünsün, bir dil ki ruhumuzla birlikte bir yasın umutsuzluğuyla ağlasın. Bir dil ki sinirlerimizin heyecanına eşlik ederek çırpınsın... Haniya bir kemanın telinde tutulamaz anlaşılamaz bir kural altına alınamaz ezgiler olur ki ruhu titretir... Haniya fecirden evvel ufuklara hafif bir renk kaynaşmasıyla dağılmış sisler olur ki üzerlerinde resmolunamaz, belirlenemez yansımlar uçar; bakışlara öpücükler serper... Haniya bazı gözler olur ki sonsuz karanlıklarla dolu bir ufka açılmış kadar ölçülemez, nerede biteceğini anlamanın mümkün olmadı̆̆ı derinlikleri vardır, duyguları yutar... İşte bir dil istiyoruz ki onda o ezgiler, o renkler, o derinlikler olsun. Firtınalarla gürlesin, dalgalarla yuvarlansın, rüzgârlarla sarsılsın; sonra veremli bir kızın yatağı kenarına düşsün ağlasın, bir çocuğun beşiğine eğilsin gülsün, bir gencin umutla parlayan bakışına saklansın. Bir dil... Oh! Saçma söylüyorum, sanacaksınız, bir dil ki sanki bütünüyle insan olsun."

Şairler, o dönemde şiirde tek bir aruz ölçüsü değil de her duyguyu için farklı 'aruz kalıbı kullanmak istemişlerdir. Bu durumu da romanda 107. sayfada Ahmed Cemil, Hüseyin Nazmi'ye şu ifadelerle açıklar.

“...Mesela hüzünlü bir parça 'feülün feülün feülün' ölçüsüyle üzüntülü bir edada sürüklene sürüklene gidip dururken sonra 'mefailün feilatün mefailün feilün' ölçüsüyle bir duygu taşıması, bir ifade hiddeti, bir nazım fışkırması, daha sonra 'müstef'ilün müstef'ilün'le bir sessizlik; sonra mesela ara yere girivermiş bir ıstırap hıçkırı̆̆ı, sanki mızrabın bir hiddet çimdiğini andıran tek bir 'ulün'..."
Servet-i Fünûn edebiyatında öne çıkan bir diğer konu ise düş - gerçek çatışmasıdır. O dönemin yazarlarında da Mai ve Siyah romanında da hayal ve gerçek ikilemlerine rastlanılmaktadır. Romanda sayfa $167^{\prime}$ de Ahmed Cemil'in Bon Marché'de Hüseyin Nazmi'nin kardeşi Lamia'yla karşılaştıktan sonraki düşünceleri bu konuya örnek olarak gösterilebilir:

“...Zihninde bu şiir dinletisi için özel bir oda düzenliyor, Lamia'yı orada bir kanepeye oturtuyor, kendisi de ta ayaklarının dibine küçük bir ayak iskemlesine oturuyor; sonra titrek bir aşk sesiyle bütün düşüncelerinin, duygularının bileşkesi olan bu şiir parçalarını bir sevda ezgisi gibi onun üzüntülü gözleri altında okuyordu. Ah! O sevda dakikası! Acaba mahrum hayatında o mutlu saat çalacak mı? Alnında bu soru bir endişe çizgisi oluşturuyordu. Kendi kendine, 'Niçin onun benimle evlenmesini istemesinler?' diyordu. O da kendisini sevmiyor mu? Bir saat önce o kendisine gülümseyen gözlerde bir gizli kapılma manası hissolunmuyor muydu? Bu aralık, ta yanı başında koşan bir kız kumların üzerine yüzükoyun düştü. Başını çevirdi, çocuk iri mai gözleriyle ona bakıyordu, yerinden kalktı, çocuğun ellerinden tuttu, kaldırdı... Bu olay onu gerçeğe döndürmüş oldu." Ancak romanın sonunda Lamia'nın başka birisiyle evlenmesi, Ahmed Cemil'in hayalinin gerçekleşememesine neden olmuştur.

Ayrica 105. sayfadaki Ahmed Cemil'in kafasında tasarladığı, uzun zamandır yazmak istediği ancak her yazdığında bir şeylerin eserinde eksik olduğunu düşündüğü, romandaki ifadeyle "beyninin içinde bir çocuk gibi yaşatıp büyüttügü, her dakika işleyip süslediği" eser hakkındaki düşünceleri de bu konuya verilebilecek bir başka örnektir.

"Zihninde düzenlediği temel pek sadeydi: Bir taze ruh $\mathrm{ki}$ hayata bir umut parıltısıyla açılıyor, güya gökyüzünün el değmemiş göğsüne güneşin öpücügünden, onun sevda dudaklarının dokunuşundan tutuşmuş bir bahar sabahı... Fakat sonra yavaş yavaş ufuklar yanmaya, etrafa bir ateş havasının baygınlıkları yayılmaya başlıyor, o saf ve taze ruha hayatın ilk dertleri yavaş yavaş sokuluyor. Hayat kavgası... Daha sonra ümit güneşi o kırılmış kalbin emel yıkıntısına hüzünlü bir ayrılık bakışıyla süzülüp gidiyor: O zaman sonucun kara bulutları... İşte eser buydu, bu eserle Ahmed Cemil insan hayatını yazmak istiyordu; başından sonuna kadar bir şiir ki bir gülümseyişle başlasın, bir damla gözyaşıyla son bulsun." Ve yine bu hayalini de Lamia'nın başka birisiyle evleneceğini öğrendikten sonra bir işe yaramayacağını düşünerek şiir kitabını sobaya atarak yakmıştır.

Servet-i Fünûn şairleri şiirlerinde daha süslü ve ilgi çekici kelimeler kullanmak istemişlerdir. Bunun romandaki bir örneği 134. Sayfadaki Ahmed 
Cemil'in bu konu hakkındaki düşüncelerinden anlayabiliriz.

"Bu âlemde bir hoşluk olmak gerekse onun bir başka tarzda olmasını gerekeceğini düşünürdü. Onda bir hastalık vard, her şeyde hatta yoksullukta, fuhuşta bile bir süs, bir zarafet olmasını isterdi. Temelde çirkin olan bu şeylerin hiç olmazsa aldatıcı gösterileri olması lazım geleceğine inanırdı."

Bu dönemin şairleri hayal ettikleri şiirleri mevcut kelimelerle yazamayacaklarını düşündüklerinden bilinmeyen, daha ilgi çekici ve anlam bakımından daha zengin kelimeler istemişlerdir. Bu konu Mai ve Siyah romanında da sayfa 142'de Ahmed Cemil'in şiir yazmak için kelime arayışında şu ifade ile belirtir.

“Bir aralık dili dar buldu. Yeni düşünceler için yeni kelimeler gerektiğinde 1srarlıydı. 'Eski kelime altında düşüncelerin tazeliği görülemez. Dikkatten kaçar.' derdi, sözlüklere sarıldı, sayfaları çevirdikçe öyle şeyler buldu ki şaştı. Bunlar niçin sözlük köşelerinde unutulmuş? Ne güzel şeyler keşfetti! Kimisinin bir düşüncesinin uyuşmasıyla, bazısının var olanlara üstünlügüne, bir bölümünün de yeniliğine kapılarak bunları sahiplenmek istedi. Kendi kendisine, 'Beni kelime uydurmakla suçlayacaklarmış. Anlamayanlar suçlasın. Sözlügüun havsalasına sı gamayacak kadar garip kelimeleri bir yere toplayan eski zaman düz yazı ustalarıyla benim yapacağım şey arasındaki sanat farkını elbette anlayan olur' derdi."

Mai ve Siyah romanında görülen bir diğer özellik ise 'ah, oh, of' gibi ifadelerin bulunmasıdır. Romanda bu ifadeler siklikla görülmektedir. Bunlardan bazıları sayfa 42 'deki;

"O zamana kadar henüz hayatın ilk bölümünü bile okumamıştı, Ah! Okulda geçirdiği zamanlar." İfadeleri ile sayfa $176^{\prime}$ daki;

“Varlığının ta derinliklerinde ruhunu keşfedip de onu kopararak kahredici bir pençe içinde sıkan, ezen, öldüren fakat tatlı bir azap içinde öldüren o siyah gözlerin karşısında bir dakika daha bulunmak, ona, 'evet, biraz daha sık, biraz daha öldür, oh! Sarhoş oluyorum, öldükçe hayat buluyorum!' demek isterdi." ifadeleri bulunmaktadır. Ayrıca bu konu hakkında kitabın 59. 128. ve 134. sayfalarında da örnekler görülmektedir.

Servet-i Fünûn edebiyatında şairler şiirde duygu ve düşünceleri kelimelerle ifade ederek adeta bir resmini yapmaya çalışmışlardır. Romanın elimizdeki baskısının 105. sayfada bu konunun açık bir örneği bulunmaktadır:

“Fakat istediğini yapamamaktan, düşündüğünü kalemine resmettirememekten kaynaklanan bir umutsuzlukla her yazdı ğı parçadan sonra o parçaya veremediği ruhun yasını tutardı."

Yukarıda verilen örneklerle batılı anlamda yazılan ilk roman olan Mai ve Siyah romanının Servet-i Fünûn edebiyatı özelliklerini, edebiyatın kurmaca gücüyle somutlaştırıp yansıtan bir roman olduğunu söylemek mümkündür ki bu bilgiler literatürde roman ile ilgili belirtilmiş özelliklerle örtüşmektedir.

\section{SONUÇ VE TARTIŞMA}

Halit Ziya Uşaklıgil'in Mai ve Siyah romanının Servet-i Fünûn edebiyatı döneminde ve bu dönemin öğretilmesindeki önemi büyüktür. Mai ve Siyah romanını incelediğimizde romanın Servet-i Fünûn edebiyatı döneminde yazılan şiir ve romanların özelliklerini kapsadığı örneklerle açıklanmıştır ve yine roman incelendiğinde Servet-i Fünûn dönemindeki yazar ve şairlerin sosyal hayatlarını, şiir ve roman yazma sanatı hakkındaki düşüncelerini, hayal ve gerçek çatışmalarını yansıttığı açıkça görülmektedir. Sonuç olarak Mai ve Siyah romanı Servet-i Fünûn edebiyatını her yönden yansıtmaktadır. Servet-i Fünûn edebiyatı konusu işlenirken 11. sınıf öğrencileri tarafından Mai ve Siyah romanının eleştirel ve analitik bir şekilde okunması dönemin özelliklerini kavranmasına, zihninde canlandirmasına yardımc1 olacağı görülmektedir. Halit Ziya Uşaklıgil'in Mai ve Siyah romanının Servet-i Fünûn edebiyatının önemli bir parçası olduğu, romanın içerisinde Servet-i Fünûn edebiyatının özelliklerini taşıyan çok sayıda örnek olduğu, romanın adeta Servet-i Fünûn'un kurgusal yansıması olduğu tespit edilmiştir. Türk edebiyatının önemli devirlerini daha iyi anlama konusunda bu gibi romanların ayrı bir işlevi bulunmaktadır. Buna dayanarak Mai ve Siyah romanının özellikle 11. sınıfların konusu olan Servet-i Fünûn işlenirken okutulması ve üzerinden örneklerle somutlaştırılarak konunun daha ilgi çekici, anlaşılabilir bir hâle gelmesi mümkündür ki bu ögrencilerde edebiyat dersinin dil ve edebiyat alanında pek çok amacına hizmet edecektir.

\section{KAYNAKLAR}

Akay, H. (2006). "Türk Dünyası Edebiyat Tarihi, Servet-i Fünûn Topluluğu ve Şiiri maddesi" Atatürk Kültür Merkezi Başkanlığı Yayınları, (9): 557-567.
Akyüz, K. (1990). Modern Türk Edebiyatının Ana Çizgileri 1860-1923: İnkılâp Kitabevi. İstanbulTürkiye. 
Baş, S. (2010). "Batıya Hayran Bir Neslin Romanı: Servet-i Fünûn Romanı". Turkish Studies, 5 (2): 333.

Çakır, Ö. (2009). "Servet-i Fünun Edebiyatının Öğretiminde Görsel Materyal Kullanımının Önemi". Mustafa Kemal Üniversitesi Sosyal Bilimler Enstitüsü Dergisi, 6 (11): 211-236.

Kılıç Gündoğdu, A. (2009) “Mai ve Siyah Romanında Tasvirler ve Yüklendiği Fonksiyonlar". Yayınlanmamış Yüksek Lisans Tezi, Adnan Menderes Üniversitesi, Sosyal Bilimler Enstitüsü. Aydın-Türkiye.

Karatay, H. (2015). “Eleştirel Düşünme ve Okuma Alışkanlığı Becerilerinin Geliştirilmesi İçin Edebiyat Halkası: Kitap Eleştirisi Modeli". Milli Eğitim ve Sosyal Bilimler Dergisi, 44 (208): 6-17.
MEB (2011). “Ortaöğretim Türk Edebiyatı Dersi 9, 10, 11 Ve 12. Sinıflar Öğretim Programı". Talim ve Terbiye Kurulu Başkanlığı. Ankara-Türkiye.

Memic, E., Doğan, E. (2016). “Halit Ziya Uşaklıgil'in Ş. Kutlu Tarafından Sadeleştirilmiş Mai ve Siyah'1 Üzerine Bir İnceleme". Teke, 5 (2): 720-739.

Mengi, M. (2007). “Metin İncelemesi Aşamaları, Terimleri ve Bunlardan Biri: Metin Tahlili" Turkish Studies / Türkoloji Araştırmaları, 2(3): 407-417.

Uşaklıgil, H. Z. (2016). Mai ve Siyah: Can Yayıncılık. İstanbul-Türkiye. 